\title{
Neurogenesis in Adult Canary Telencephalon Is Independent of Gonadal Hormone Levels
}

\author{
Susan D. Brown, Frank Johnson, and Sarah W. Bottjer \\ Department of Biology, University of Southern California, Los Angeles, California 90089-2520
}

\begin{abstract}
Neurons generated in adulthood are found throughout the canary telencephalon. We are interested in the factors that control the rate of proliferation of stem cells that give rise to these new neurons. The rate of incorporation of newly generated neurons into vocal-control regions varies seasonally. This difference could reflect a higher rate of neurogenesis, a lower rate of cell death, or an altered migration. We examined the incidence of thymidine-labeled cells in the telencephalic ventricular zone of adult canaries as a function of variations in gonadal hormone levels. Adult female canaries maintained on a short-day photoperiod were anesthetized and gonadectomized. Four separate groups of birds received systemic exposure to either testosterone, estradiol, a combination of an anti-androgen and an inhibitor of estrogen synthesis, or nothing. All birds were also implanted with an osmotic minipump that released ${ }^{3} \mathrm{H}$-thymidine for 3 $\mathrm{d}$ and were killed 4 or $7 \mathrm{~d}$ following the onset of treatment. Analysis of autoradiograms revealed no differences between groups in the incidence of labeling within the ventricular zone either at the level of the anterior commissure or directly adjacent to the vocal-control nucleus HVC (higher vocal center). These results suggest that sex steroids do not regulate the rate of cell division in the ventricular zone. Seasonal differences in the incorporation of labeled cells into HVC may therefore be due to regulation of neurogenesis by photoperiodic factors other than gonadal steroids or to some other cellular mechanism, such as differential migration or survival of neurons.
\end{abstract}

[Key words: neurogenesis, songbird, steroid hormones, testosterone, estradiol, flutamide]

Neurons gencratcd in adulthood are found throughout the canary telencephalon (Alvarez-Buylla and Nottebohm, 1988; Alvarez-Buylla, 1990). New neurons originate in the ventricular zone (VZ) of the lateral ventricles, where proliferating cells are found primarily along the ventrolateral walls of the lateral ventricles (Goldman and Nottebohm, 1983; Alvarez-Buylla et al., 1988, 1990a). Cells from the VZ appear to migrate along radial glia and become incorporated in diverse regions of the telencephalon (Alvarez-Buylla and Nottebohm, 1988). One target region for these new neurons is a telencephalic nucleus, HVC (higher vocal center), involved in the control of vocal behavior

\footnotetext{
Received May 21, 1992; revised Sept. 11, 1992; accepted Nov. 13, 1992.

We thank Michelle Godfrey for technical assistance and the Schering Corporation for providing flutamide. This research was supported by NIH Grant DC00190 to S.W.B. and by Training Fellowship 2 T32 AG00093 (S.D.B. and F.J.).

Correspondence should be addressed to Susan D. Brown at the above address. Copyright (c) 1993 Society for Neuroscience 0270-6474/93/132024-09\$05.00/0
}

(Goldman and Nottebohm, 1983). New neurons in HVC are incorporated into functional circuits (Paton and Nottebohm, 1984; Burd and Nottebohm, 1985), and many form long axonal projections to another telencephalic song-control nucleus, RA (robust nucleus of the archistriatum), which projects to the motor neurons that innervate the vocal organ (Alvarez-Buylla et al., 1988, 1990b; Kirn et al., 1991). The number of neurons in HVC does not increase with age; thus, the continual addition of new neurons presumably represents the replacement of neurons that are lost (Kirn and Nottebohm, 1991; Alvarez-Buylla et al., 1992). While the continual addition of new neurons to support constantly growing organisms such as fish has been reported (see, e.g., Birse et al., 1980; Easter, 1983), neuronal addition in which new neurons join functional circuits to replace neurons that are lost in fully grown adult animals has so far been reported in only a few systems (Bayer et al., 1982; Gueneau et al., 1982). The mechanisms by which this neuronal replacement is accomplished should therefore be of general interest.

Male canaries sing seasonally, and the rate of incorporation of new neurons into HVC varies seasonally as well (AlvarezBuylla et al., 1990b). When maintained on a North American light cycle, canaries begin to sing a "plastic" or variable song in October or November, and develop a stable stereotyped song by January, the beginning of the breeding season. The songs themselves are modified seasonally by the addition of new song elements and the deletion of others (Nottebohm and Nottebohm, 1978; Nottebohm et al., 1986). Hormone levels vary seasonally as well; testosterone levels are higher in April and May when birds are singing than in September and October when they are not (Nottebohm et al., 1987). When canaries are treated with radiolabeled thymidine and their brains are examined for the incidence of labeled neurons 4 months later, birds treated in October (when song is variable and hormone levels are low) have a larger number of labeled neurons in HVC than do birds treated with labeled thymidine in May (when song is stable and hormone levels are high; Alvarez-Buylla et al., 1990b; Kirn et al., 1991).

Female canaries rarely produce male-typical vocalizations, and ncver producc loud, stablc song patterns characteristic of males in breeding condition (Pesch and Güttinger, 1985). The neural substrate underlying song is also sexually dimorphic; for example, HVC is much larger in males than in females (Nottebohm and Arnold, 1976). However, adult females treated systemically with exogenous testosterone begin to produce malelike song, and the size of $\mathrm{HVC}$ almost doubles, approaching that of male canaries (Nottebohm, 1980). The hormone-induced growth of HVC in females reflects an increase in the number of neurons, including an increase in the number of hormone-concentrating cells (Bottjer and Dignan, 1988; Brenowitz and Ar- 
nold, 1990; Bottjer and Maier, 1991). Hormone treatment also influences the size of HVC in males, both as identified in Nisslstained tissue and as defined by the distribution of both projection neurons and androgen-concentrating cells (Johnson and Bottjer, 1991, 1993; but cf. Gahr, 1990).

This experiment addresses the question of whether hormones regulate the rate of cell proliferation in the VZ. That is, if a link between hormone levels and incorporation of new neurons exists, is the mechanism to be found in the regulation of cell proliferation? We treated female canaries with hormones or anti-steroid drugs and examined the amount of cell proliferation in the VZ following short survival times when cell migration or cell death would play a negligible role in determining the number of labeled cells in the VZ. We observed no differences in the incidence of thymidine-labeled cells even between birds in which circulating gonadal steroids were high and those in which the action of hormones was pharmacologically blocked. This observation indicates that gonadal steroids do not regulate the rate of cell proliferation in the VZ of adult canary telencephalon.

\section{Materials and Methods}

Hormone administration and thymidine labeling. Twenty adult female canaries (Serinus canaria) at least 12 months old were obtained from local suppliers and used in this study. Female canarics werc used because the female song system is relatively undeveloped compared to that of males, yet the female song system grows dramatically in response to hormone treatment and the number of neurons in HVC increases. Thus, female canaries should provide the most optimal means for detecting hormone-induced changes in proliferation rates. In order to control for nonhormonal photoperiod effects, the birds were maintained on a constant short-day photoperiod (10 hr light, $14 \mathrm{hr}$ dark) beginning 4-7 months prior to the start of the experiment.

Each bird was anesthetized by intramuscular injection of Equithesin, and the ovary was removed by aspiration. Immediately after surgery one or two Silastic implants containing steroid hormone, anti-steroid drugs, or solid Silastic were inserted subcutaneously over the pectoral muscles. The implants consisted of a length of Silastic tubing (i.d. 0.76 $\mathrm{mm}$, o.d. $1.65 \mathrm{~mm}$; Dow Corning) packed with $5 \mathrm{~mm}$ crystalline tcstosterone, 17- $\beta$-estradiol, 1,4,6-androstatrien-3,17-dione (ATD; an aromatase inhibitor that blocks the conversion of testosterone to estradiol; Lieberburg et al., 1977; Alexandre and Balthazart 1987), flutamide (an anti-androgenic drug that binds to androgen receptors; Peets et al., 1974; Neri, 1977), or Silastic glue. The open ends of the implants were sealed with Silastic glue, which was allowed to cure, and incubated overnight in avian saline. Incubation begins the process of diffusion of the hormone or drug across the Silastic, ensuring that release begins immediately upon implantation and continues at a relatively constant rate throughout the treatment period (Smith et al., 1977). Hormone-treated birds received one implant containing either testosterone $(n=8)$ or 17 $\beta$-estradiol $(n=4)$; control birds received either one or two solid Silastic implants $(n=4)$, or one flutamide and one or two ATD implants (total number of implants in the flutamide/ATD group was either two or three; $n=4$ ).

Each bird was also implanted with a microosmotic pump (Alzet model 1003D) filled with $100 \mu \mathrm{l}$ of tritiated thymidine (methyl- ${ }^{3} \mathrm{H}$-thymidine; specific activity, $6.7 \mathrm{Ci} / \mathrm{mm}$; New England Nuclear) as a sterile, aqueous solution. These pumps dispensed thymidine at a rate of $1.06( \pm 0.05)$ $\mu \mathrm{l} / \mathrm{hr}$ for $3 \mathrm{~d}$, resulting in a dosage of about $1.5 \mu \mathrm{Ci} / \mathrm{gm} / \mathrm{d}$. Constant infusion of thymidine rather than one or several "pulse" injections was chosen for its greater sensitivity. That is, small changes in proliferation rates that extend over a long period of time are more likely to be detected with constant infusion than with acute doses (Marsman et al., 1988).

Preparation of brain tissue. Birds survived $4(n=12)$ or $7(n=8) \mathrm{d}$ following onset of thymidine administration (i.e., 1 or $4 \mathrm{~d}$ following the end of thymidine exposure; see Table 1). All birds were deeply anesthetized with Equithesin and perfused transcardially with $0.75 \%$ salinc followed by buffered formalin, and the brains were removed and postfixed for 1-2 weeks in the same fixative. The brains were then dehydrated with graded concentrations of ethyl alcohol, cleared in methyl salicylate, and embedded in paraffin at $57^{\circ} \mathrm{C}$. Coronal $6 \mu \mathrm{m}$ sections were cut using
Table 1. $n$ values for different treatment groups

\begin{tabular}{lll} 
& \multicolumn{2}{l}{ Survival times } \\
\cline { 2 - 3 } Treatment & $4 \mathrm{~d}$ & $7 \mathrm{~d}$ \\
\hline Testosterone & 4 & 4 \\
$17-\beta$-Estradiol & 4 & - \\
Flutamide/ATD & 2 & 2 \\
Nothing & 2 & 2 \\
\hline
\end{tabular}

a rotary microtomc. Evcry fourth scrics of five sections was mountcd on chrom-alum-subbed slides ( $30 \mu \mathrm{m}$ on each slide, $90 \mu \mathrm{m}$ between slides) and dipped in nuclear track emulsion (Kodak NTB3). Sections were stored for 4 weeks at $4^{\circ} \mathrm{C}$, developed for 4 min at $15^{\circ} \mathrm{C}$ (Kodak D19), washed, and stained with thionin.

Analysis of autoradiograms. The autoradiograms were examined under bright-field illumination for the presence of labeled cells in the ependymal layer of the lateral ventricles, the origin of neurons generated in adulthood (Alvarez-Buylla and Nottebohm, 1988; Alvarez-Buylla et al. 1990a). Changes in the number of newly generated neurons could result from a larger number of stem cells dividing, an increase in the rate at which stem cells divide, or from both processes acting together. We wanted to use the most sensitive measure of changes in the amount of cell division, and in addition, to sample a relatively large region of the VZ. Wc also wanted to avoid the problem of cstablishing an arbitrary criterion for deciding whether individual cells were labeled. For example, cells of some birds in the $7 \mathrm{~d}$ survival groups could have divided at a high rate during the $4 \mathrm{~d}$ after thymidine treatment ended, resulting in a reduced number of silver grains per cell, and the (erroneous) classification of these cells as unlabeled using an arbitrary criterion of three or five times background. In order to obviate this problem, we counted the total number of silver grains (adjusted for background levels of labeling) throughout the entire telencephalic $\mathrm{VZ}$ of individual brain sections. Measuring the total incidence of silver grains along the VZ should provide the most sensitive measure of cellular proliferation, since it provides a direct index of the amount of DNA replication and therefore reflects all instances of mitotic activity (i.e., a larger number of stem cells entering the cell cycle and/or a fixed population of cells dividing at a higher ratc) regardlcss of any preset critcrion.

The amount of proliferation varies within the $\mathrm{VZ}$ and is particularly high in so-called "hot spots." For example, the lateral wall of the ventral portion of the ventricle at the level of the anterior commissure contains a large number of dividing cells, whereas fewer dividing cells are found in the dorsal portion of the $\mathrm{VZ}$ at this level and in more caudal regions of the ventricle (Alvarez-Buylla and Nottebohm, 1988). Changes in the amount of proliferation in the VZ could occur either in "hot spots," which could become even more active, or within regions that normally show low rates of proliferation. We therefore chose to examine the incidence of labeling along the full extent of the lateral ventricle around the level of the anterior commissure, in order to sample regions of both higher and lower proliferation.

A video-imaging system (Analytical Imaging Concepts) was used to measure the number of silver grains within a spccificd rcgion of the brain. The background level of labeling was calculated for each section by measuring the number of silver grains per unit area within a region in the adjacent parenchyma devoid of obviously labeled cells. The number of silver grains along entire ependymal zone lining the lateral ventricular wall facing the brain parenchyma was measured at the level of the anterior commissure as well as $1 \mathrm{~mm}$ anterior and posterior to this level. Two nonadjacent sections were measured at each level. These silver grain counts were compiled to obtain the total number of silver grains found within the VZ at these levels. The total number of silver grains was corrected for background levels of labeling (based on the average background levels throughout all sections measured) by expressing the measure as a ratio of the number of silver grains actually observed to the number of silver grains expected for a region of the same size if the incidence of labcling was not different from background levels.

We also measured the incidence of labeling within regions of both high and low proliferation separately. Within each section, the VZ was subdivided into consecutive adjacent regions in which the number of 
silver grains were measured individually. This was accomplished by counting silver grains in separate regions that encompassed a segment of the VZ in which a subjectively similar level of labeling was found. That is, all of a lightly labeled segment of the VZ was included within one region while an adjacent heavily labeled segment was included in a separate region. We established a criterion for characterizing each of these regions as "labeled" or "unlabeled" based on the number of silver grains found in the region compared to background levels of labeling. The incidence of labeling within each region was expressed as the number of times background labeling, and an individual region was considered to be labeled if the total number of silver grains overlying it was at least three times the expected grain count (i.e., if the incidence of silver grains over the region was $\geq 3 \times$ the incidence of background labeling). In some cases, the results were also compared using a more stringent criterion of 10 times the incidence of background labeling. Each brain was then characterized by calculating the ratio of the size of labeled regions to the total area measured to arrive at a measure the percentage of regions that were labeled. In addition, labeled and unlabeled regions were separately compared across treatment groups (see below).

For the $7 \mathrm{~d}$ survival group, the incidence of labeling over individual cells was calculated as well. The distribution of grain counts per cell provide an indication of the rate of cell division; within a population of relatively rapidly dividing cells, the distribution would shift toward a larger number of cells with fewer silver grains. Such a change would be most noticeable in the $7 \mathrm{~d}$ survival groups in which the birds survived for $4 \mathrm{~d}$ beyond the termination of thymidine infusion. By comparing the distributions of silver grains over cells for the different treatment groups, the relative rate of cell division within the VZ could be assessed. Some individual cells were very tightly clustered or overlapped, making the number of silver grains over individual cells frequently impossible to distinguish. However, in many cases individual cells could be distinguished throughout the VZ, including some within heavily labeled areas. A sample of approximately 100 individual cells per bird in the $V Z$ of the lateral wall of the ventral portion of the ventricle was analyzed using the same image analysis system. The number of silver grains overlying every individually discernable labeled cell in the $\mathrm{VZ}$ was counted in one to three sections at the level of the anterior commissure. The number of silver grains over each cell was compiled to obtain a distribution of silver grain counts over individual cells.

The source of newly generated neurons found within IIVC is not known, but the nucleus lies directly beneath the lateral ventricle within the caudal neostriatum, and the shortest route for a migrating neuron to take into HVC would be from the overlying VZ. With this in mind, we counted the number of individual labeled cells in the $\mathrm{VZ}$ overlying $\mathrm{HVC}$ and within a $0.2-\mathrm{mm}$-wide region within $\mathrm{HVC}$ adjacent to the $\mathrm{VZ}$ in the $7 \mathrm{~d}$ survival group. Because the size of HVC varied considerably between individual birds, we compared the number of labeled cells per millimeter of VZ examined. The length of VZ overlying $\mathrm{HVC}$ was measured by tracing it using a camera lucida and measuring the length of the tracing using a digitizing tablet (SIGMASCAN, Jandel Scientific). The number of labeled cells within HVC (but outside the VZ) was also noted. Three sections, evenly spaced throughout the anteriorposterior axis of $\mathrm{HVC}$, were examined for each bird.

\section{Results}

Many areas of the VZ were very heavily labeled in all birds, and the VZ was considerably hypertrophied in some areas, appearing similar to the pseudostratified epithelium that has been described in early mammalian development (Sauer, 1935; Seymour and Berry, 1976) rather than as a monolayer of cells (see Fig. 1). Measures of the incidence of labeling within the $\mathrm{VZ}$ were compared across treatment groups in three ways: (1) the overall amount of cell proliferation was compared using the total number of silver grains adjusted for background, (2) the size of the proliferating population of cells was compared by measuring the percentage of measured regions that were labeled, and (3) the amount of cell proliferation within labeled and unlabeled regions was compared separately.

Overall incidence of cell proliferation. The ratio of the total number of silver grains observed to the expected number of silver grains was measured in six sections for each bird. This measure of the overall amount of cell division in the VZ did not differ as a function of hormone treatment for either the $4 \mathrm{~d}$ survival groups $[F(3,7)=0.420, p=0.744]$ or the $7 \mathrm{~d}$ survival groups $[F(2,5)=0.836, p=0.486$; see Fig. 2]. No pairwise differences between any of the groups were significant, indicating that the total amount of thymidine label, and by inference the amount of DNA replication, did not differ as a function of hormone levels.

Size of the proliferating population. One way in which gonadal steroids could regulate cell proliferation is by inducing previously quiescent stem cells to enter the mitotic cycle. To evaluate this possibility in a different way, the total area of the labeled regions ( $\geq 3 \times$ background labeling) of the $\mathrm{VZ}$ was expressed as a percentage of the total area measured. This measure of the size of the proliferating population did not differ as a function of hormone treatment for either the $4 \mathrm{~d}$ survival groups $[F(3,7)$ $=0.477, p=0.708]$ or the $7 \mathrm{~d}$ survival groups $[F(2,5)=0.888$, $p=0.468$; see Fig. 3]. This was true even if a more stringent critcrion for considering a given region to be labeled $(10 \times$ background) was used (data not shown). No pairwise differences between any of the treatment groups were found, indicating that the proportion of the VZ composed of labeled areas, a measure of the size of the population of proliferating cells, did not differ as a function of hormone treatment. Because the proportion of the VZ composed of unlabeled areas is exactly complementary to the proportion composed of labeled areas, the proportion of unlabeled areas also did not differ as a function of hormone treatment.

Incidence of silver grains in labeled and unlabeled regions. The areas of the VZ that we sampled contained both highly proliferative areas (which we designated as labeled regions) as well as relatively quiescent, nonproliferative areas (designated as unlabeled regions). Hormone-induced changes in proliferation rates within either of these two populations of cells could be masked by a lack of changes in the other population in our measures of proliferation in the $\mathrm{VZ}$ as a whole. For example, relatively small changes in the proliferation rates of "hot spots" might be undetectable when large nonproliferative regions are included in the overall measurement; conversely, small increases in the proliferation rate within normally nonproliferating regions could be undetectable when included with high indices of proliferation from "hot spots." Therefore, we compared the incidence of labeling for labeled regions and unlabeled regions separately. When the average incidence of silver grains was measured for the labeled regions only, no differences were found between hormone treatments for either the $4 \mathrm{~d}[F(3,7)=0.302$, $p=0.823]$ or $7 \mathrm{~d}$ survival time $[F(2,5)=0.832, p=0.488$; see Fig. 4]. No pairwise differences between any of the groups were significant, indicating that the total amount of thymidine label within labeled regions of the $\mathrm{VZ}$, and by inference the amount of DNA replication, docs not differ as a function of hormone levels in the proliferating regions.

When the total number of silver grains was measured for the unlabeled regions only ( $<3 \times$ background labeling), no differences were found between treatment groups for either the $4 \mathrm{~d}$ $[F(3,7)=0.216, p=0.882]$ or 7 d survival time $[F(2,5)=0.980$, $p=0.438$; data not shown]. The incidence of silver grains in the unlabeled regions of all groups (expressed as the number of times background) did not differ from 1 , the expected value if the incidence of labeling was equal to background labeling (mean $=0.986 \pm 0.205 ; t=-0.068$, NS). Thus, the regions we con- 

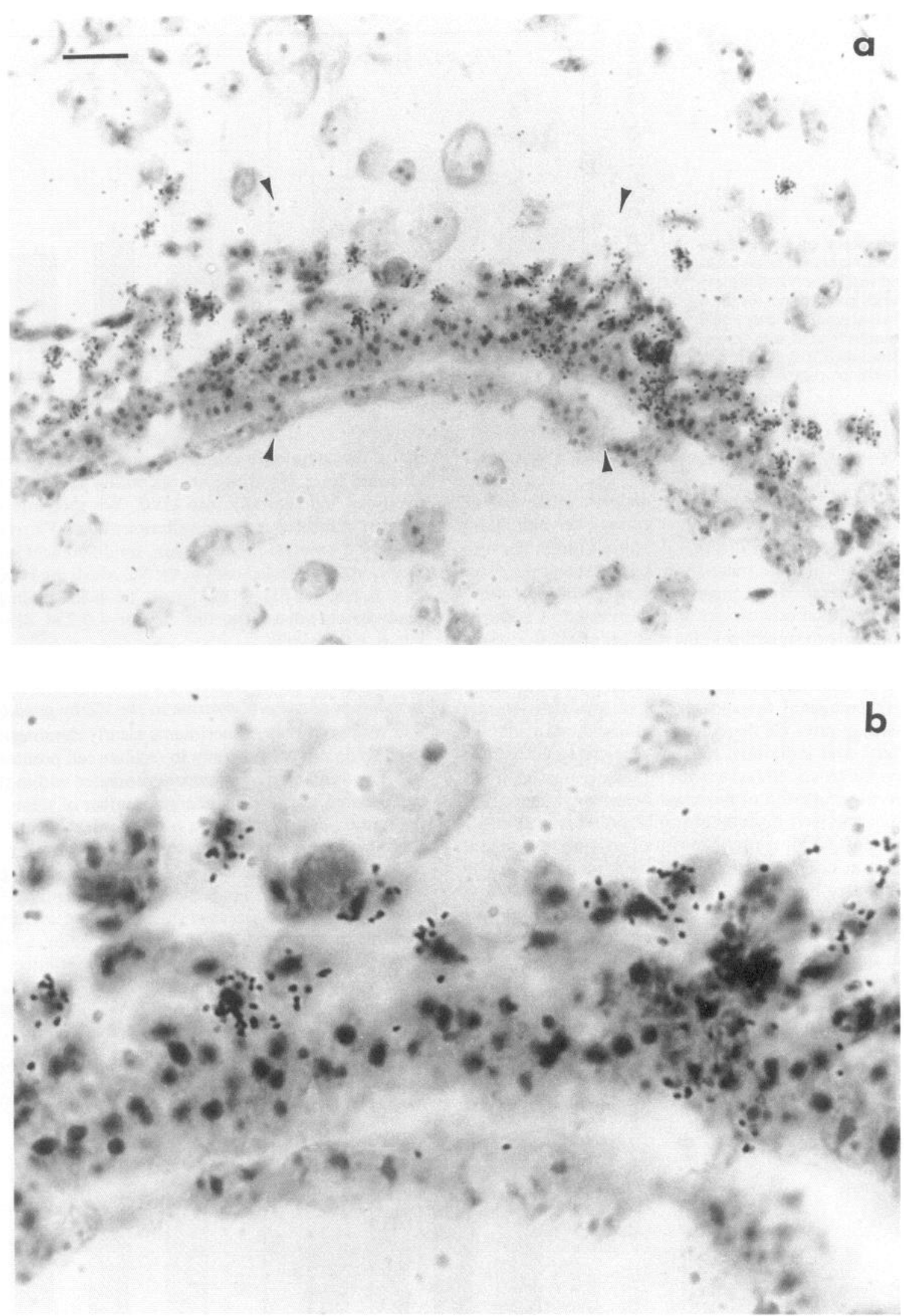

Figure 1. Autoradiograms showing thymidine-labeled cells in the $\mathrm{VZ}$ of the lateral wall of the ventral portion of the lateral ventricle at the level of the anterior commissure. Arrowheads on $a$ indicate the area shown in $b$. Scale bar, $20 \mu \mathrm{m}$ for $a$. 
Figure 2. Incidence of silver grains (expressed as the number of times background) found within the VZ at the level of the anterior commissure for the 4 $\mathrm{d}$ and $7 \mathrm{~d}$ survival groups (mean $\pm \mathrm{SD}$ ) in female canaries treated with testosterone ( $T)$, estradiol $(E 2)$, flutamide and ATD $(F L / A T D)$, or control implants $(C T L)$.

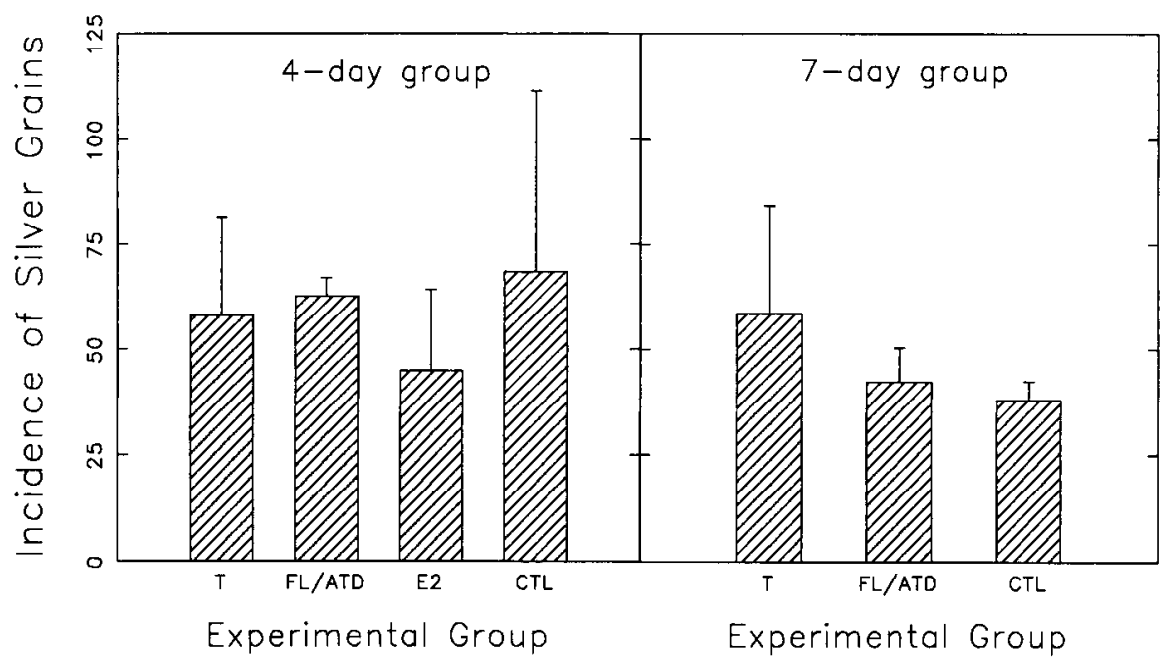

sidered to be unlabeled did not appear to contain a significant number of proliferating cells.

Rate of cell proliferation. An indirect measure of the rate of cell proliferation, the number of silver grains over individual cells, was measured for the $7 \mathrm{~d}$ survival groups as well. Because the radiolabeled thymidine was administered chronically for a period of $3 \mathrm{~d}$ (rather than as a single pulse), the number of silver grains over individual cells would not be expected to occur in integer multiples corresponding to the number of cell divisions. However, the number of silver grains over individual cells would nevertheless be reduced in a population of cells that was dividing more rapidly, compared to a population of cells that was dividing at a slower rate. We therefore examined the distribution of grain counts over individual cells for each treatment within the $7 \mathrm{~d}$ survival group. No systematic differences between the distributions as a function of hormone treatment were found, indicating that cells were dividing at similar rates in the different treatment groups (Kolmogorov-Smirnov two-sample comparisons, maximum difference always $<0.110, p$ always $>0.1$; Conover, 1980; see Fig. 5).

Labeling adjacent to $H V C$. Descriptions of seasonal differences in the rate of incorporation of newly generated neurons have been limited to the nucleus HVC. Although the location of the stem cells giving rise to new neurons found in $\mathrm{HVC}$ is unknown, this nucleus lies directly below the dorsolateral por- tion of the lateral ventricle in the caudal neostriatum. The shortest route for a migrating neuron would therefore be from the overlying $\mathrm{VZ}$ ventrally into $\mathrm{HVC}$. We therefore counted the number of labeled cells per millimeter in the VZ overlying HVC in the $7 \mathrm{~d}$ survival group. Again, no differences were found in the number of labeled cells in the VZ overlying $\mathrm{HVC}(t=1.621$, $\mathrm{df}=5$, NS; see Fig. 6 , left panel), or in the brain parenchyma immediately adjacent to this zone $(t=0.234$, df $=5$, NS; see Fig. 6, right panel).

\section{Discussion}

Regulation of cell proliferation in the $V Z$ by gonadal steroids The results of these experiments clearly demonstrate that sex steroids do not act generally to regulate cell proliferation in the $V Z$. The number of new neurons generated within the VZ could be regulated by inducing a larger number of stem cells to enter the mitotic cycle, inducing a fixed number of cells to divide at a faster rate, or both processes acting in concert. If either of these two possible mechanisms for increased cell proliferation occurred, the overall incidence of thymidine label found in the VZ would increase. Because thymidine was administered continuously over a period of $3 \mathrm{~d}$ in our procedure, a larger number of labeled daughter cells would result from either higher proliferation rates or a larger number of dividing stem cells. However, overall indices of labeling were no different for the various
Figure 3. Percentage of $\mathrm{VZ}$ areas at the level of the anterior commissure that were labeled ( $\geq 3 \times$ background) for the $4 \mathrm{~d}$ and $7 \mathrm{~d}$ survival groups (mean \pm $\mathrm{SD}$ ) in female canaries treated with testosterone $(T)$, estradiol $(E 2)$, flutamide and ATD $(F L / A T D)$, or control implants $(C T L)$.

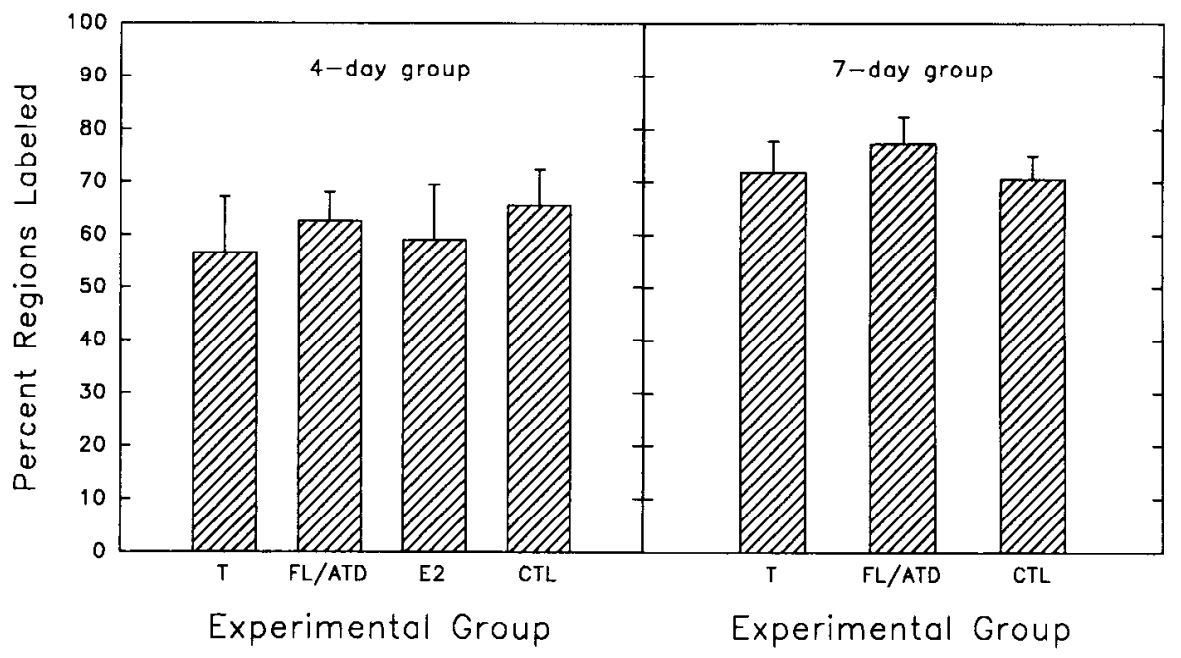




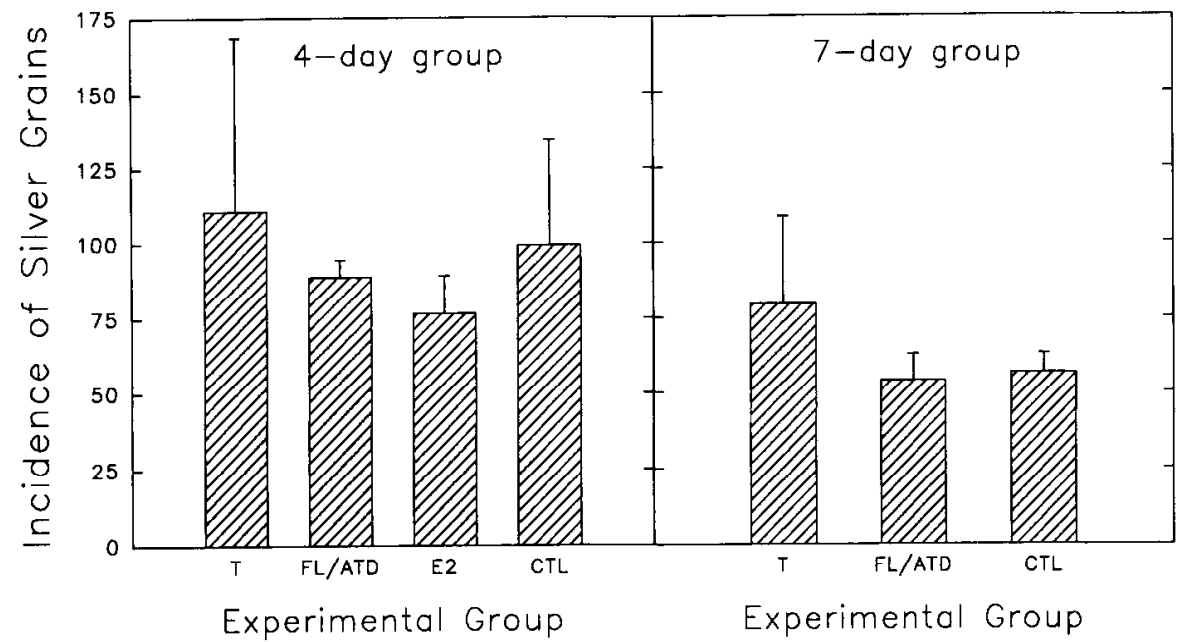

Figure 4. Incidence of silver grains (expressed as number of times background) within labeled areas ( $\geq 3 x$ background) for the $4 \mathrm{~d}$ and $7 \mathrm{~d}$ survival groups (mean $\pm \mathrm{SD}$ ) in female canaries treated with testostcrone $(T)$, cstradiol $(E 2)$, flutamide and ATD $(F L / A T D)$, or control implants $(C T L)$. treatment groups, nor did the incidence of labeling in the $\mathrm{VZ}$ adjacent to HVC differ as a function of hormone treatment. No differences were found even when heavily labeled and lightly labeled regions of the $\mathrm{VZ}$ were considered separately, indicating that hormone treatment did not act to regulate preferentially either a normally active or a normally quiescent population of stem cells. The proportion of labeled to unlabeled regions also did not vary with hormone treatment, suggesting that the overall size of the population of proliferating stem cells did not vary with hormone treatment.

If stem cells in the $\mathrm{VZ}$ were dividing at different rates as a result of hormone treatment, then the distribution of numbers of silver grains over individual cells would change. This difference would be most noticeable in the $7 \mathrm{~d}$ survival group, which survived for $4 \mathrm{~d}$ following the end of a $3 \mathrm{~d}$ exposure to thymidine, allowing ample time for labeled cells to divide more than once. Our results show no differences in the distribution of the number of silver grains over individual cells, indicating that the rate of proliferation of stem cells was constant across hormone treatment groups. Differences in gonadal steroid levels, then, do not appear to regulate the overall incidence of proliferation, the proliferation of cells in the VZ overlying $\mathrm{HVC}$, the number of stem cells that are dividing, or the rate of proliferation of stem cells along the lateral ventricles.

Although the results of our study clearly indicate that sex steroids do not modulate overall rates of cell proliferation in the telencephalic VZ of canaries, the rate of cell proliferation in the $\mathrm{VZ}$ of young female ring doves is higher than that of young males (Ling and Cheng, 1991). These findings suggest either that sex differences in neurogenesis are regulated by factors other than gonadal steroids, or alternatively, a possible species difference between canaries and ring doves. In another songbird species, the zebra finch, a larger number of newly generated cells are incorporated into $\mathrm{HVC}$ of juvenile males than of juvenile females (Nordeen and Nordeen, 1988). While this finding does not demonstrate sex differences in neurogenesis (see below), our results suggest that if sex differences in neurogenesis exist, they are probably not regulated by gonadal steroids.

Seasonal differences in the rate of incorporation of neurons into $H V C$

Previous studies have reported scasonal differences in the rate of incorporation of new neurons into $\mathrm{HVC}$ of adult male ca- naries; a larger number of neurons generated in the fall are subsequently incorporated into HVC than are neurons generated in the spring (Alvarez-Buylla et al., 1990b; Kirn et al., 1991). We found no differences in proliferation of the stem cells in the $\mathrm{VZ}$ following hormone treatment, suggesting that seasonal variations in the levels of gonadal steroids probably do not act to regulate cell proliferation in the $\mathrm{VZ}$.

Instead, the present results suggest that if observed seasonal differences in the incorporation of neurons into $\mathrm{HVC}$ reflect differences in the rate of cell proliferation, other seasonal or photoperiod-related factor(s) must be involved. A variety of growth factors, related receptors, and protooncogene products have potent mitogenic effects on various cell types. Very little

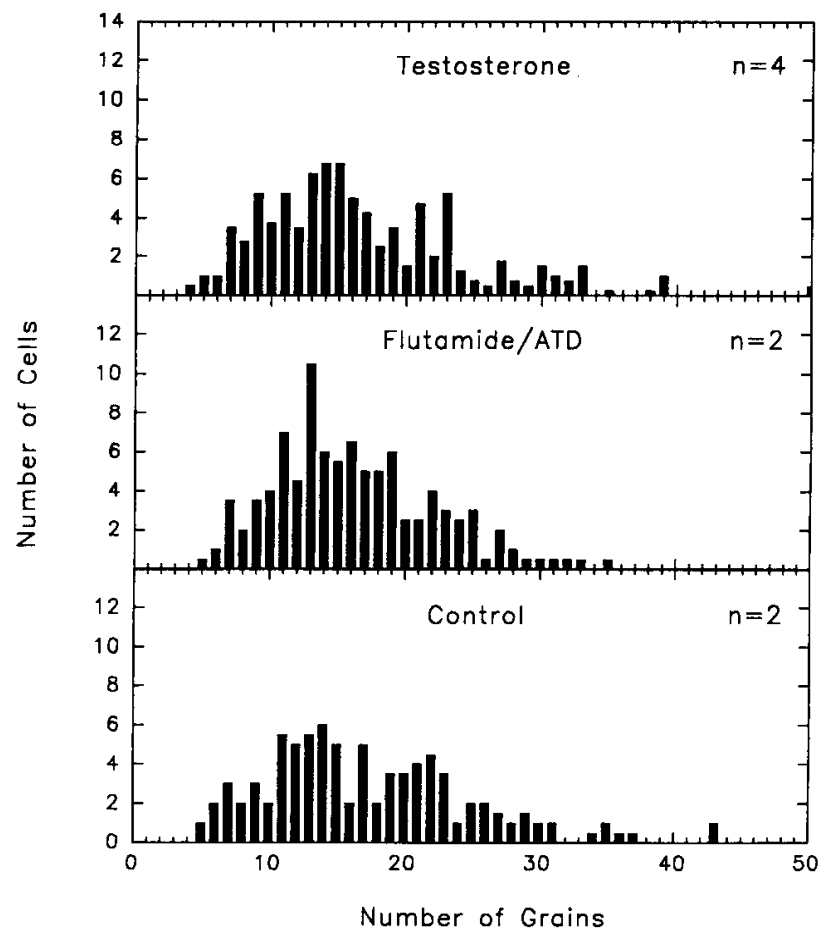

Figure 5. Histograms of the number of silver grains over individual cells within the $\mathrm{VZ}$ at the level of the anterior commissure for the testosterone, flutamide and ATD, and control birds in the $7 \mathrm{~d}$ survival group. 
Figure 6. Number of labeled cells in the VZ dorsal to HVC, and in adjacent parenchyma within $\mathrm{HVC}$ (mean $\pm \mathrm{SD}$ ) for the testosterone $(T)$, flutamide and ATD $(F L / A T D)$, and control birds $(C T L)$ in the $7 \mathrm{~d}$ survival group.

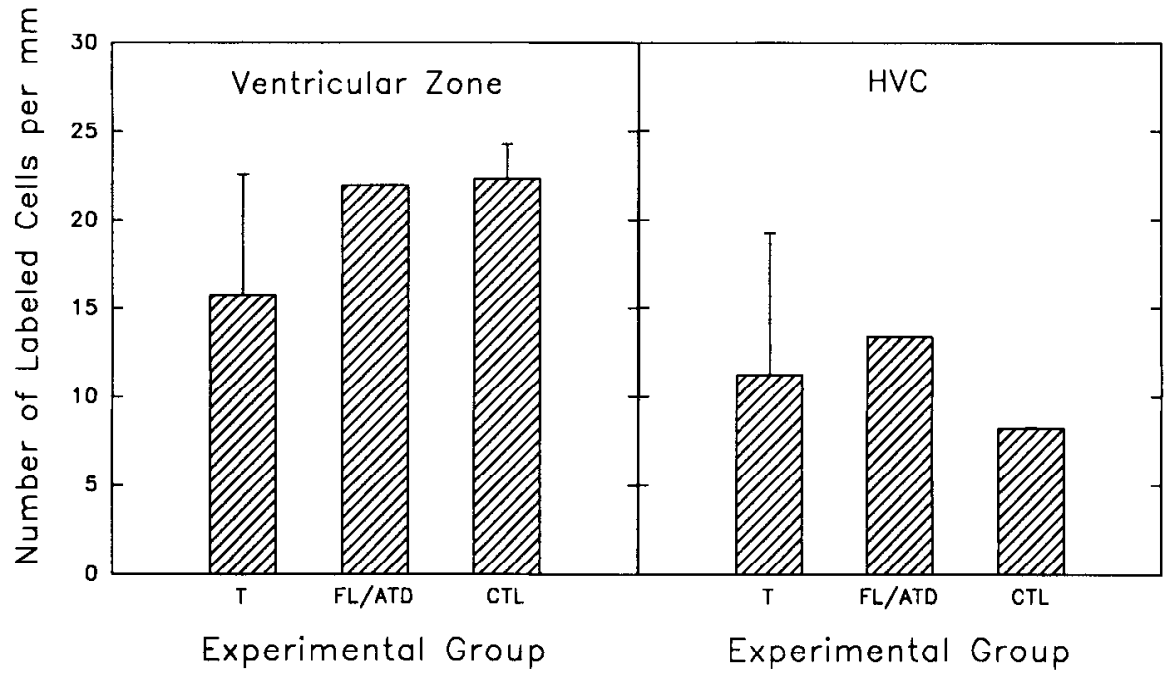

is known concerning seasonal regulation of growth factors. However, a recent report demonstrated photoperiod-induced changes in blood levels of insulin-like growth factor I (IGF-I) in reindeer (Suttie et al., 1991). This finding is particularly intriguing because IGF-I has been shown to be mitogenic for sympathetic neuroblasts in vitro (DiCicco-Bloom and Black, 1988). To our knowledge, IGF-I is the only growth factor that has been reported to vary seasonally. However, other growth factors and their receptors have been localized to the $\mathrm{VZ}$ in developing mammalian and avian systems during periods of neurogenesis (e.g., Heuer et al., 1990; Maisonpierre et al., 1990; Wanaka et al., 1991; Lillien and Cepko, 1992). For example, the studies by Heuer et al. (1990) and Wanaka et al. (1991) indicate that levels of mRNA for fibroblast growth factor receptor are high in the ependymal layer of the CNS during embryonic development in both chick and rat. Whether specific growth factors or their receptors are preferentially expressed in the ependymal zone of adult canary telencephalon is not known. However, growth factors could vary seasonally and thereby influence the incidence of proliferation in $\mathrm{VZ}$ of the canary brain.

An alternative interpretation of our results is that there are no seasonal differences in neurogenesis within canary brain. That is, cellular proliferation in the VZ may occur in some ongoing "constitutive" fashion. All of the studies reporting seasonal differences in neurogenesis have utilized long survival times following thymidine labeling. Therefore, no direct evidence for or against differences in the overall rate of cell proliferation in the VZ of adult songbirds exists, because long survival times allow for other cellular mechanisms, such as differential cell death or altered migration, to intervene following neurogenesis and potentially influence the number of labcled neurons present months later. For example, neurogenesis may continue at a constant rate in the adult canary brain, and seasonal differences in the number of neurons incorporated into $\mathrm{HVC}$ may instead reflect differences in the survival rates of specific populations of cells. Following short survival times, many thymidine-labeled cells that appear to be migrating are pyknotic, and fewer labeled cells are found in the brain parenchyma following longer survival times than are seen in the VZ following very short survival times (Alvarez-Buylla et al., 1990a). These results suggest that many of the migrating cells die before reaching a final location. Differences in the number of new neurons that are incorporated into HVC could in part reflect differences in the number of migrating neuroblasts that survive the journey, but the extent to which this mechanism plays a role in this system and the factors that might regulate neuronal survival are unknown. Effects of steroid hormones on cell survival in other systems have been documented (e.g., Nordeen et al., 1985; Weeks and Truman, 1986), and estrogen treatment is thought to prevent the death of RA neurons in female zebra finches (for review, see Bottjer and Johnson, 1992). Thus, ample precedent for hormonal regulation of neuron survival exists.

Cell death may also play a role at a later stage, that is, after neurons migrate into HVC. One way in which hormones could regulate the survival of neurons in HVC is by effecting changes in the efferent target of newly generated cells. Many newly generated neurons in HVC project to RA (Alvarez-Buylla et al., $1990 \mathrm{~b}$; Kirn et al., 1991). Increases in the level of testosteroneinduce growth of RA, and survival of at least some of the newly generated neurons in HVC may depend on changes within this target nucleus. In female canaries treated with exogenous testosterone, the number of synaptic sites within RA increases as does the size of the dendritic arbor of RA neurons (DeVoogd and Nottebohm, 1981; DeVoogd et al., 1985). Similar morphological changes may underlie seasonal changes reported in the volume of RA in male canaries (Nottebohm, 1981). These changes may make for a more hospitable environment for a newly generated cell when forming connections within a previously established pathway.

Differential regulation of neurogenesis may occur only for subpopulations of stem cells (specific to HVC) that have not yet been identified. The location of the specific stem cells that give rise to new neurons found in the song system is unknown. Hormones may act only on a restricted population of cells in the $\mathrm{VZ}$, the source of new neurons in HVC, but this population has not yet been identified. Thus, one caveat concerning our results is that we may not have sampled that part of the $\mathrm{VZ}$ that gives rise to new HVC neurons. If gonadal hormones were to influence a restricted set of stem cells giving rise to HVC neurons, they could do so either indirectly or directly. With the latter idea in mind, we scanned the VZ more broadly around the level of both $\mathrm{HVC}$ and the anterior commissure in brains of adult female 
canaries that had been treated with radiolabeled testosterone and processed for steroid autoradiography (Bottjer and Maier, 1991). Cells in the VZ around these two locations do not appear to concentrate testosterone (S. D. Brown, F. Johnson, and S. W. Bottjer, unpublished observations). However, since the location of the subpopulation of stem cells for HVC is unknown, direct action by hormones on these cells remains possible.

Limited neurogenesis has been reported for restricted populations of cells in the adult vertebrate brain, that is, dentate gyrus in rat and rabbit and the receptors of the olfactory system (Birse et al., 1980; Bayer et al., 1982). Because neurogenesis is not widespread in these species, some subpopulation of stem cells is likely to be differentially regulated to continue to proliferate in adulthood while most other stem cells are not. Similarly, regulation of the proliferation rates of stem cells in the songbird brain may also be heterogeneous, a fact already demonstrated by the presence of hot spots (and by a lack of adult neurogenesis anywhere outside of the telencephalon; AlvarezBuylla and Nottebohm, 1988).

Hormone effects on neurogenesis may be temporally complex. Seasonal variations in the levels of gonadal steroids of adult canaries are somewhat complicated. Testosterone levels of male canaries rise and fall several times throughout the year, with peaks occurring both in the spring (April/May) and in midwinter (November/December). Estradiol levels also rise and fall, with three peaks during the year in midwinter (November/December), early spring (March/April), and midsummer (June/July; Nottebohm et al., 1987). Any seasonal effects that are mediated by hormone levels, then, would not necessarily occur as a simple spring/fall difference, but might instead follow a more complex temporal pattern. In other systems, the response of a population of cells to hormones depends on previous history of hormone exposure (see, e.g., Weeks and Truman, 1986).

Hormones may interact with other factors to regulate neurogenesis. Hormones may act indirectly to regulate neurogenesis through an intermediate step. For example, steroid hormones may stimulate the release of growth or trophic factors that act on a population of stem cells that are not themselves steroid targets. Similarly, steroid hormones could also regulate neurogenesis by inducing the expression of receptors for another factor. If mechanisms such as these are involved in neurogenesis in the canary brain, the effects of steroid hormones may not have been apparent in this experiment if the process of stimulation of another factor or inducing the expression of a receptor takes longer than the $3 \mathrm{~d}$ that labeled thymidine was present.

A second possibility is that hormones may interact synergistically with other factors to promote neurogenesis. For example, estradiol and IGF-I interact to promote neurite outgrowth (Toran-Allerand et al., 1988), and interactions between growth factors have been shown to regulate Schwann cell mitosis (Schubert, 1991). These studies raise the possibility that both a steroid hormone and a growth factor may be required for substantial changes in the incidence of neurogenesis to occur.

Conclusions. Gonadal steroid hormones alone do not appear to regulate neurogenesis in the telencephalon of adult canaries. Neurogenesis may continue at a constant rate, and the number of neurons incorporated into specific brain regions such as $\mathrm{HVC}$ may be regulated by other cellular mechanisms, such as cell death, in which steroid hormones may play a role. If neurogenesis is differentially regulated (e.g., seasonally), then some other factor, acting alone or together with stcroid hormones, must be involved.

\section{References}

Alexandre C, Balthazart J (1987) Inhibition of testosterone metabolism in the brain and cloacal gland of the quail by specific inhibitors and antihormones. J Endocrinol 112:189-195.

Alvarez-Buylla A (1990) Mechanism of neurogenesis in adult avian brain. Experientia 46:948-955.

Alvarez-Buylla A, Nottebohm F (1988) Migration of young neurons in adult avian brain. Nature 335:353-354.

Alvarez-Buylla A, Theelen M, Nottebohm F (1988) Birth of projection neurons in the higher vocal center of the canary forebrain before, during, and after song learning. Proc Natl Acad Sci USA 85:87228726 .

Alvarez-Buylla A, Theelen M, Nottebohm F (1990a) Proliferation "hot spots" in adult avian ventricular zone reveal radial cell division. Neuron 5:101-109.

Alvarez-Buylla A, Kirn JR, Nottebohm F (1990b) Birth of projection neurons in adult avian brain may be related to perceptual or motor learning. Science 249:1444-1446.

Alvarez-Buylla A, Ling C-Y, Nottebohm F (1992) High vocal center growth and its relation to neurogenesis, neuronal replacement and song acquisition in juvenile canaries. J Neurobiol 23:396-406.

Bayer SA, Yakel JW, Puri PS (1982) Neurons in the rat dentate gyrus granular layer substantially increase during juvenile and adult life. Science 216:890-892.

Birse SC, Leonard RB, Coggeshall RE (1980) Neuronal increase in various areas of the nervous system of the guppy, Lebistes. J Comp Neurol 194:291-301.

Bottjer SW, Dignan TP (1988) Joint hormonal and sensory stimulation modulate neuronal number in adult canary brains. J Neurobiol 19: 624-635.

Bottjer SW, Johnson F (1992) Matters of life and death in the songbird forebrain. J Neurobiol 23:1172-1191.

Bottjer SW, MaierE (1991) Testosterone and the incidence of hormone target cells in song-control nuclei of adult canaries. J Neurobiol 22: 512-521.

Brenowitz EA, Arnold AP (1990) The effect of systemic androgen treatment on androgen accumulation in song control regions of the adult female canary brain. J Neurobiol 21:837-843.

Burd GD, Nottebohm F (1985) Ultrastructural characterization of synaptic terminals formed on newly generated neurons in a song control nucleus of the adult canary forebrain. J Comp Neurol 240: 143-152.

Conover WJ (1980) Practical nonparametric statistics. New York: Wiley.

DeVoogd T, Nottebohm F (1981) Gonadal hormones induce dendritic growth in the adult avian brain. Science 214:202-204.

DeVoogd T, Nixdorf B, Nottebohm F (1985) Synaptogenesis and changes in synaptic morphology related to acquisition of a new behavior. Brain Res 329:304-308.

DiCicco-Bloom E, Black IB (1988) Insulin growth factors regulate the mitotic cycle in cultured sympathetic neuroblasts. Proc Natl Acad Sci USA 85:4066-4070.

Easter SS (1983) Postnatal neurogenesis and changing connections. Trends Neurosci 6:53-56.

Gahr M (1990) Delineation of a brain nucleus: comparisons of cytochemical, hodological, and cytoarchitectural views of the song control nuclcus HVC of the adult canary. J Comp Ncurol 294:30-36.

Goldman SA, Nottebohm F (1983) Neuronal production, migration and differentiation in a vocal control nucleus of the adult female canary brain. Proc Natl Acad Sci USA 80:2390-2394.

Gueneau G, Privat A, Drouet J, Court L (1982) Subgranular zone of the dentate gynus of young rabbits as a secondary matrix. A high resolution autoradiographic study. Dev Neurosci 5:345-358.

Heuer JG, von Bartheld CS, Kinoshita Y, Evers PC, Bothwell M (1990) Alternating phases of FGF receptor and NGF receptor expression in the developing chicken nervous system. Neuron 5:283-296.

Johnson F, Bottjer SW (1991) Testosterone regulates the distribution and number of androgen target cells in canary HVC. Soc Neurosci Abstr 17:1052.

Johnson FJ, Bottjer SW (1993) Testosterone-induced changes in identificd cell populations of the higher vocal center of mole canaries. $J$ Neurobiol, in press.

Kirn JR, Nottebohm F (1991) Naturally occurring projection neuron loss in the song control system of the adult canary. Soc Neurosci Abstr $17: 876$. 
Kirn JR, Alvarez-Buylla A, Nottebohm F (1991) Production and survival of projection neurons in a forebrain vocal center of adult male canaries. J Neurosci 11:1756-1762.

Lieberburg I, Wallach G, McEwen BS (1977) The effects of an inhibitor of aromatization $(1,4,6$-androstatriene-3,17-dione $)$ and an anti-estrogen (Cl-628) on in vivo formed testosterone metabolites recovered from neonatal rat brain tissues and purified cell nuclei. Implications for sexual differentiation of the rat brain. Brain Res 128:176-181.

Lillien L, Cepko C (1992) Control of proliferation in the retina: temporal changes in responsiveness to FGF and TGF $\alpha$. Development 115:253-266.

Ling C, Cheng M-F (1991) Cell proliferation in the ventricular zone of ring doves. Soc Neurosci Abstr 17:30.

Maisonpierre PC, Belluscio L, Friedman B, Alderson RF, Wiegand SJ, Furth ME, Lindsay RM, Yancopoulos GD (1990) NT-3, BDNF, and NGF in the developing rat nervous system: parallel as well as reciprocal patterns of expression. Neuron 5:501-509.

Marsman DS, Cattley RC, Conway JG, Popp JA (1988) Relationship of hepatic peroxisome proliferation and replicative DNA synthesis to hepatocarcinogenicity of the peroxisome proliferators di(2-ethylhexyl)phthalate and [4-chloro-6-(2,3-xylidino)-2-pyrimidinylthiolacetic acid (Wy-14,643) in rats. Cancer Res 48:6739-6744.

Neri RO (1977) Studies on the biology and mechanism of action of nonsteroidal antiandrogens. In: Androgens and antiandrogens (Martini L, Motta M, eds), pp 163-177. New York: Raven.

Nordeen EJ, Nordeen KW (1988) Sex and regional differences in the incorporation of neurons during song learning in zebra finches. $J$ Neurosci 8:2869-2874.

Nordeen EJ, Nordeen KW, Sengelaub DR, Arnold AP (1985) Androgens prevent normally occurring cell death in a sexually dimorphic spinal nucleus. Science 229:671-673.

Nottebohm F (1980) Testosterone triggers growth of brain vocal control nuclei in adult female canaries. Brain Res 189:429-436.

Nottebohm F (1981) A brain for all seasons: cyclical anatomical changes in song control nuclei of the canary brain. Science 214:1368-1370.

Nottebohm F, Arnold AP (1976) Sexual dimorphism in vocal control areas of the songbird brain. Science 194:211-213.

Nottebohm F, Nottebohm ME (1978) Relationship between song rep- ertoire and age in the canary, Serinus canarius. Z Tierpsychol 46 : 298-305.

Nottebohm F, Nottebohm ME, Crane L (1986) Developmental and seasonal changes in canary song and their relation to changes in the anatomy of song-control nuclei. Behav Neural Biol 46:445-471.

Nottebohm F, Nottebohm ME, Crane LA, Wingfield JC (1987) Seasonal changes in gonadal hormone levels of adult male canaries and their relation to song. Behav Neural Biol 47:197-211.

Paton JA, Nottebohm F (1984) Neurons generated in the adult brain are recruited into functional circuits. Science 225:1046-1048.

Peets EA, Henson MF, Neri R (1974) On the mechanism of the antiandrogenic action of flutamide ( $\alpha$ - $\alpha$ - $\alpha$-trifluoro-2-methyl-4' -nitro- $m$ propionotoluidide) in the rat. Endocrinology 94:532-540.

Pesch A, Güttinger H-R (1985) Der Gesang des weiblichen Kanarienvogels. J Ornithol 126:108-1 10.

Sauer FC (1935) Mitosis in the neural tube. J Comp Neurol 62:377405.

Schubert D (1991) Synergistic interactions between transforming growth factor beta and fibroblast growth factor regulate Schwann cell mitosis. J Neurobiol 23:143-148.

Seymour RM, Berry M (1975) Scanning and transmission electron microscopy studies of interkinetic nuclear migration in the cerebral vesicles of the rat. J Comp Neurol 160:105-126.

Smith ER, Damassa DA, Davidson JM (1977) Hormone administration: peripheral and intracranial implants. In: Methods in psychobiology (Myers RD, ed), pp 259-279. New York: Academic.

Suttie JM, White RG, Breier BH, Gluckman PD (1991) Photoperiod associated changes in insulin-like growth factor-I in reindeer. Endocrinology 129:679-682.

Toran-Allerand CD, Ellis L, Pfenninger KH (1988) Estrogen and insulin synergism in neurite growth enhancement in vitro: mediation of steroid effects by interactions with growth factors? Dev Brain Res $41: 87-100$

Wanaka A, Milbrandt J, Johnson EM Jr (1991) Expression of FGF receptor gene in rat development. Development 111:455-468.

Weeks JC, Truman JW (1986) Steroid control of neuron and muscle development during the metamorphosis of an insect. J Neurobiol 17: 249-267. 